\title{
DESMATAMENTO NAS MARGENS DA ESTRADA DA EMADE NO MUNICÍPIO DE TEFÉ-AM, UMA ANÁLISE DOS ANOS DE 1990 E 2015
}

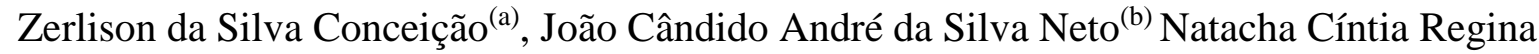 \\ Aleixo $^{(\mathrm{c})}$ \\ (a) Universidade do Estado do Amazonas, caio cortezao12@hotmail.com \\ (b) Universidade Federal do Amazonas, joaokandido@yahoo.com.br \\ (c) Universidade Federal do Amazonas, natachaaleixo@yahoo.com.br
}

Eixo: Uso e ocupação das terras e legislação ambiental

\begin{abstract}
Resumo
O presente estudo tem como objetivo geral mapear a área da Estrada da EMADE identificando o desmatamento realizado pela ação antrópica a partir da Empresa Amazonense de Dendê (EMADE) no município de Tefé-AM. Nesse estudo foi possível identificar as áreas que foram desmatadas, através do processo de análise das imagens do sensoriamento remoto dos satélites landsat 5 e 8 , em diferentes anos (1990 a 2015), processadas pelo Sistema de Informação Geográfica, o (SIG). Por meio desse procedimento foi possível obter classe de queimada, classe de desmatamento, classe de floresta, classe de corpos d'água e a classe de solo exposto. Também foram elaborados mapas para identificação da quantidade e qualidade das informações relacionadas ao desmatamento nas margens da estrada da EMADE na cidade de Tefé-AM .
\end{abstract}

Palavras chave: Desmatamento; Sistema de Informação Geográfica; Tefé; Amazonas.

\section{Introdução}

A Amazônia Brasileira tem sofrido um processo gradativo de transformações da paisagem nas ultimas décadas associadas principalmente pelo avanço das monoculturas que pressionam a região, em especial na área denominada "arco do desmatamento", que compreende parte dos estados do Rondônia, Acre, Matogrosso, Tocantins, Pará e Amazonas.

Entretanto, a substituição das áreas de florestas por atividades agropecuárias não ocorre com exclusividade no arco do desmatamento. No interior da região Amazônica esse processo ocorre, porém, de modo menos intenso, por conta de vários fatores, sobretudo pelo difícil acesso a determinadas áreas.

A estrada da EMADE, por exemplo, está localizada no município de Tefé, no interior do estado Amazonas, cujo o processo de ocupação e transformação da paisagem se iniciou com os processos de desmatamentos relacionados às questões da grilagem de terra, expansão das áreas de moradia, agricultura (plantação de mandioca). 
XVII Simpósio Brasileiro de Geografia Fisica Aplicada

I Congresso Nacional de Geografia Física
OS DESAFIOS DA GEOGRAFIA FÍSICA NA FRONTEIRA DO CONHECIMENTO

Instituto de Geociências - Unicamp

Campinas - SP

28 de Junho à 02 de Julho de 2017

A mesma caracteriza-se por ser uma pista única de mão dupla com alguns trechos sinuosos, que serve como escoamento de produtos agrícolas dos moradores. Essa estrada recebeu este nome dado por populares devido à Empresa Amazonense de Dendê (EMADE) que chegou ao município de Tefé nos anos 80 para implantar o projeto dendê na cidade.

Assim, o objetivo geral do trabalho foi mapear a área da Estrada da EMADE identificando o desmatamento realizado pela ação antrópica a partir da Empresa Amazonense de Dendê (EMADE) no município de Tefé-AM.

O município de Tefé está localizado na Região do Médio Solimões do Estado do Amazonas (Figura 1), segundo o Instituto Brasileiro de Geografia Estatística (2017) Tefé tem aproximadamente 61.000 de habitantes, sendo considerado um dos principais municípios da região, devido à estrutura de serviços, estabelecimentos de saúde, educação e outros, diferenciada dos municípios vizinhos de menor porte.

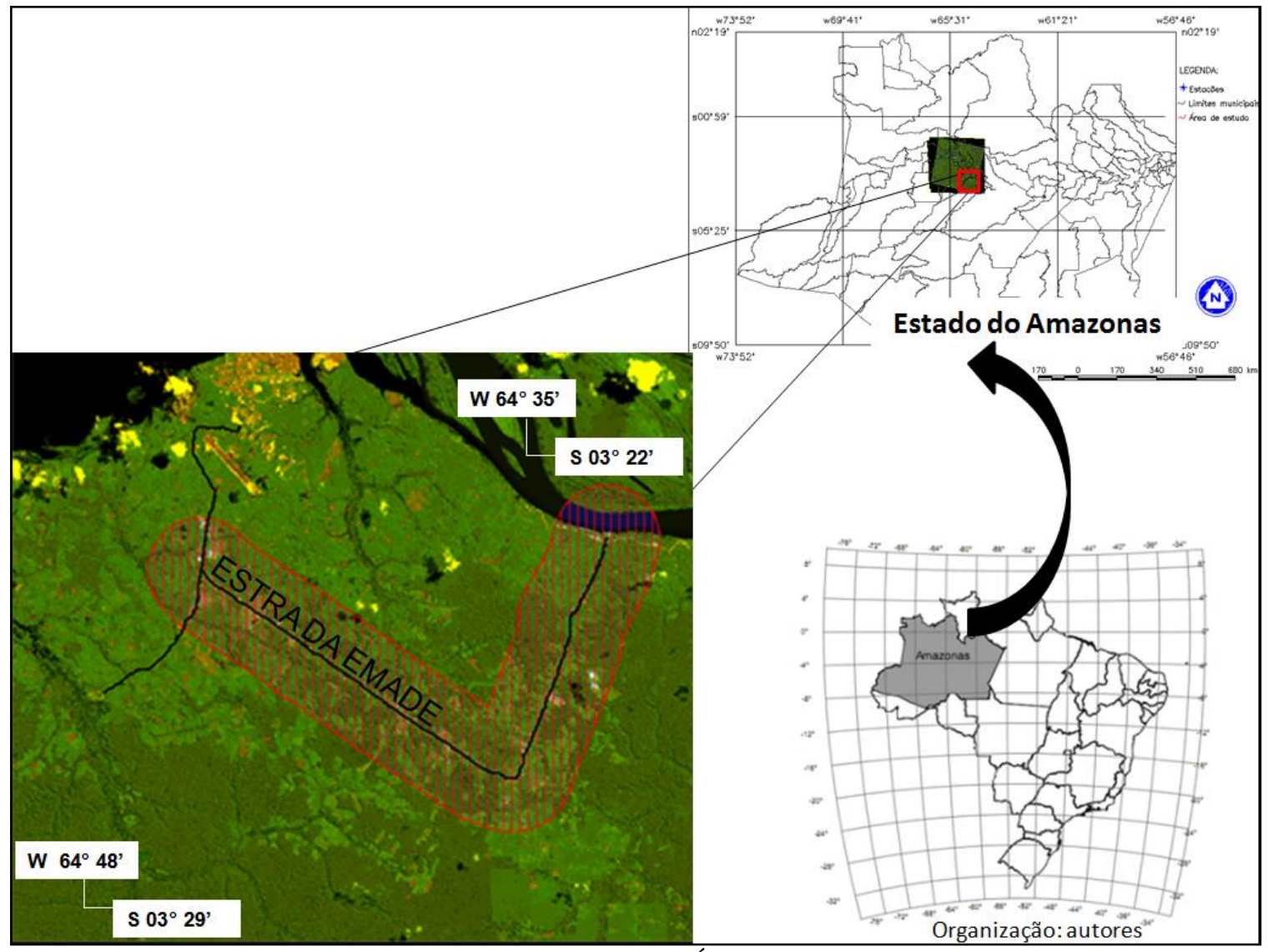

Figura 1: Localização da Área de Estudo.

O presente artigo fez uma análise referente à estrada da EMADE, a mesma possui $23 \mathrm{~km}$ de extensão, tendo em suas margens várias comunidades, ocupadas principalmente por pequenos agricultores e aldeias indígenas como: São Francisco, Boa Vontade, Santa Clara, Vila Floresta e Barreiras da missão de Baixo, 
do Meio e de Cima. A Estrada da EMADE está situada a $8 \mathrm{~km}$ da cidade de Tefé e consiste em um trecho de $23 \mathrm{~km}$, que serviria como acesso ao porto da cidade de Tefé, que nunca foi implantado.

Segundo Sindicato dos Trabalhadores Rurais de Tefé (STRT), as terras pertencentes à Empresa Amazonense de Dendê pertencem ao Banco Mundial, justamente as terras que $80 \%$ dos moradores da Estrada da EMADE estão assentados, o Sindicato através do setor de advocacia estão tentando por meio de processos judiciais, meios para que essas terras sejam legalizadas para dar os títulos de posse aos agricultores, mas até o presente momento pouco foi feito a respeito desse assunto.

Na década de 1980, com o objetivo criar um grande empreendimento para cultura de Dendê no município de Tefé, o estado do Amazonas colocou em funcionamento a Empresa Amazonense de Dendê - EMADE.

Este projeto pretendia cultivar a palma e instalar uma agroindústria dos subprodutos do dendê. Aproximadamente 26 milhões de dólares foram alocados pelo Banco Mundial - BID, porém, grande parcela dos recursos foi desviada, o que motivou seu declínio, a área desse projeto possuía 273 mil hectares de floresta, entretanto, apenas 1.400 hectares foram derrubados e no lugar de dendê iniciou-se a prática da agricultura de subsistência por 127 famílias que ocuparam a área e estão envolvidas no plantio de mandioca para a produção de farinha. Diante disso o homem se apropria da natureza e depois a transforma.

\section{Procedimentos metodológicos}

A escolha da estrada da EMADE se deu pela sua importância que tem no município de Tefé-AM e para os moradores e agricultores, pois os mesmos a utilizam para escoamento de sua produção agrícola para a área urbana. Ressalta-se que ocorre escassez de estudos sobre a temática na área.

A realização da pesquisa iniciou-se com levantamento bibliográfico de artigos, livros, teses relacionadas ao tema. Além disso, foram realizados levantamentos de dados com órgãos públicos e entrevistas com moradores mais antigos que ainda residem no local.

As imagens de satélite foram adquiridas gratuitamente no site do Instituto Nacional de pesquisas Espaciais (INPE) e United State Geological Survey (USGS), respectivamente, LANDSAT 5 TM de 14/11/1990 (cena 001_062_L2) 8 OLI de 30/07/2015 (ID cena LC80010622015211LGN00).

A etapa seguinte foi realizar as composições coloridas $R G B$ das imagens utilizando as bandas 3,4 e 5 para LANDSAT 5TM, e 4, 5 e 6 para LANDSAT 8 OLI. 


\section{OS DESAFIOS DA GEOGRAFIA FÍSICA NA FRONTEIRA DO CONHECIMENTO \\ Instituto de Geociências - Unicamp \\ Campinas - SP \\ 28 de Junho à 02 de Julho de 2017}

No passo seguinte, as imagens foram georreferenciadas e inseridas em ambiente de Sistema de Informação Geográfica, onde foram classificadas utilizando o método de classificação por regiões segmentadas, em que é possível detectar as áreas.

Após o processo de segmentação por regiões deu-se a etapa de "treinamento" que corresponde à coleta de amostras das áreas de desmatamento, solo exposto etc. A classificação consiste nas análises das amostras e categorização, com o auxílio do classificador que mede a distância entre a distribuição das probabilidades de classes espectrais.

A imagem foi processada pelo classificador BHATTACHARYA, com confiabilidade de $99,9 \%$ do resultado coletado pelo usuário, com isso, foi possível verificar através da análise das amostras a confiabilidade de acordo com cada área analisada. (figura 2).

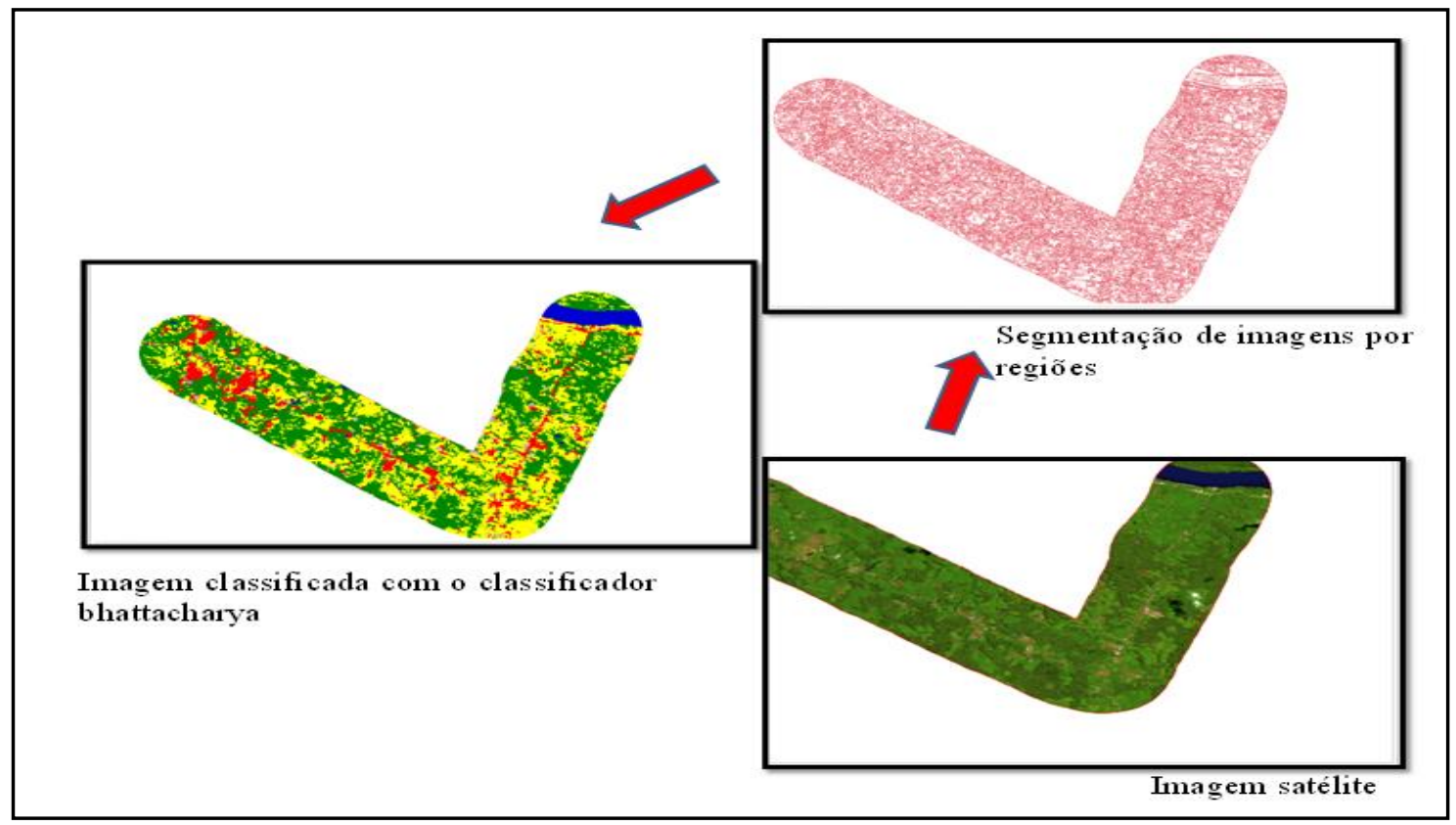

Figura 2: Procedimentos metodológicos para mapear a Estrada da EMADE. Fonte: Conceição, 2016.

No procedimento de classificação da imagem utilizou-se o software gratuito SPRING 5.4, onde foram classificadas as imagens em classes temáticas para desmatamento, queimadas, corpos d'água, solo exposto e floresta.

Após a classificação das imagens foi realizada a tabulação e tratamento dos dados a partir da planilha do Excel. A representação foi realizada por intermédio de gráficos que possibilitou a quantificação das áreas de desmatamento, queimadas, corpos d'água, solo exposto e floresta.

Assim, por meio da utilização das imagens de satélite foi possível delimitar a área da estrada da EMADE, bem como dos tipos de uso da terra e cobertura vegetal dos anos analisados. 
A classificação de imagem permite, assim, a criação de imagens virtuais da área para a realização de um posterior cruzamento das informações obtidas, ou mesmo para a elaboração de mapas temáticos (FITZ, 2008 p.131).

Segundo Fitz, (2008, p.132), “assim, uma imagem será classificada com base em determinados parâmetros definidos pelo profissional que necessariamente deverá ter conhecimento das características da área de trabalho".

Diante de todo o percurso metodológico trilhado através das novas geotecnologias, foi possível fazer a elaboração dos recortes da área de estudo (EMADE) e gerar uma imagem com processo de segmentação.

As classes de mapeamento foram definidas da seguinte forma:

- Classe floresta: para classe floresta foram classificadas as áreas da vegetação remanescente.

- Classe Desmatamento: foram classificadas as áreas de agricultura (plantação de mandioca) como forma de subsistência e atividade econômica, especulação imobiliária, pecuária e expansão urbana através de comunidades que surgem.

-Classe Corpos d'água: para a área classificada dos corpos d'água foram identificados todos os canais de drenagem.

- Classe Queimada: para a classe de queimada foram classificadas todas as áreas da utilização do plantio e pastagem (criação de gado).

- Classe Solo Exposto: para a área de solo exposto foram classificadas todas as áreas manejadas para a agricultura, em que ocorre ocupação antrópica.

\section{Desmatamento na estrada da EMADE}

O mapeamento elaborado do uso da terra e da cobertura vegetal da Estrada da EMADE, dos anos de 1990 e 2015, possibilitou a identificação das áreas de desmatamento no local.

Os dados analisados permitiram a identificação das porcentagens das áreas atingidas pelos desmatamentos, que mostrou como a paisagem foi modificada nos anos de 1990 a 2015. Assim, verificouse que a ação antrópica no decorrer do período analisado foi capaz de transformar as paisagens naturais em paisagens artificiais, como é possível observar nas figuras 3 e 4 .

Assim, a substituição das áreas de floresta, desmatamento, queimadas tem como suas consequências a perda da biodiversidade, degradação do solo, erosão e empobrecimento do solo e assoreamento dos rios. 
XVII Simpósio Brasileiro de Geografia Fisica Aplicada

I Congresso Nacional de Geografia Física
OS DESAFIOS DA GEOGRAFIA FÍSICA NA FRONTEIRA DO CONHECIMENTO

Instituto de Geociências - Unicamp

Campinas - SP

28 de Junho à 02 de Julho de 2017

Com isso, quando se compara o período analisado nos dois mapas, verificam-se as diferenças que ocorreram no decorrer dos anos e como a paisagem foi modificada.

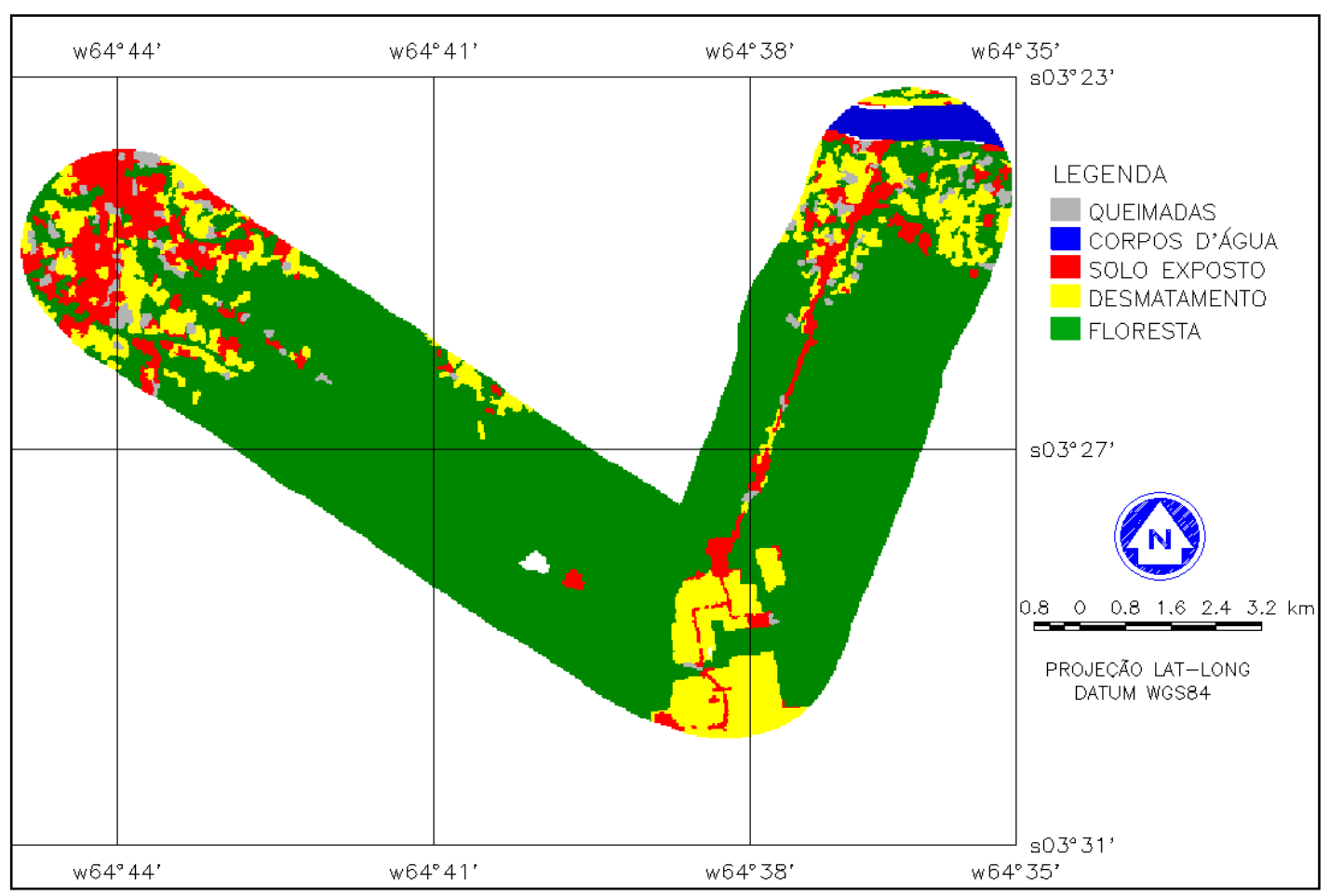

Figura 3: Mapa do uso do solo e da cobertura vegetal da estrada da EMADE, do ano de 1990.

Fonte: Autores.

Podemos observar que nas figuras 03 e 04 ocorre diferença do uso da terra, e é possível verificar as áreas mais afetadas pelos impactos causados pela ação antrópica em relação aos anos analisados, em que se nota a diminuição das classes de floresta, aumento de desmatamento, queimadas e solo exposto. 


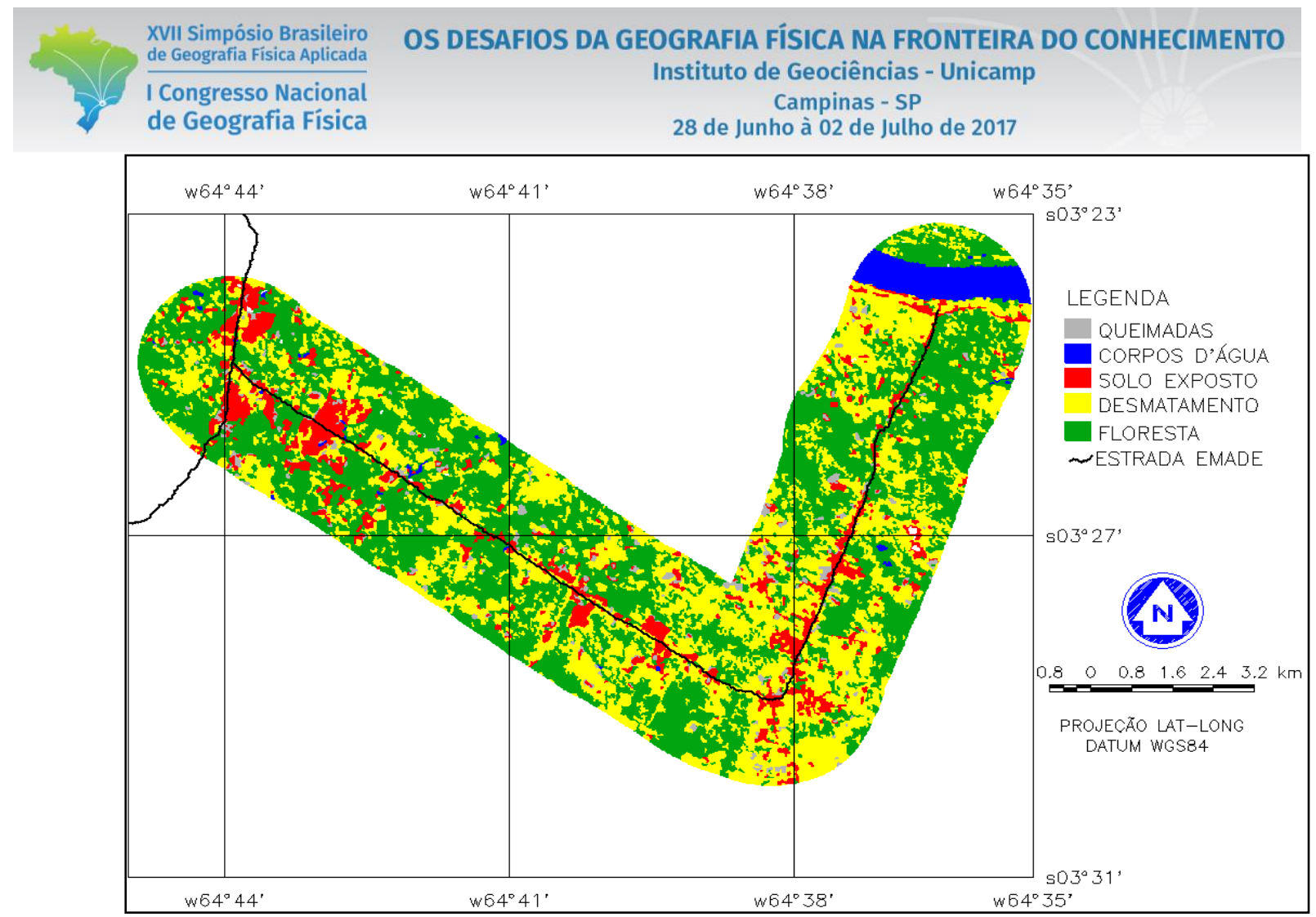

Figura 4: Mapa do uso do solo e da cobertura vegetal da estrada da EMADE, do ano de 2015. Fonte: Autores, 2016.

No gráfico 1 verifica-se que $74 \%$ da área de estudo correspondem às áreas de floresta, a outra classe de desmatamento é de $13 \%$, de solo exposto $9 \%$, áreas de queimadas foram de $2 \%$ e corpos d'água $2 \%$. Verifica-se que no ano de 1990 a predominância das áreas de floresta, e um processo de ocupação e transformação da paisagem ainda moderado.

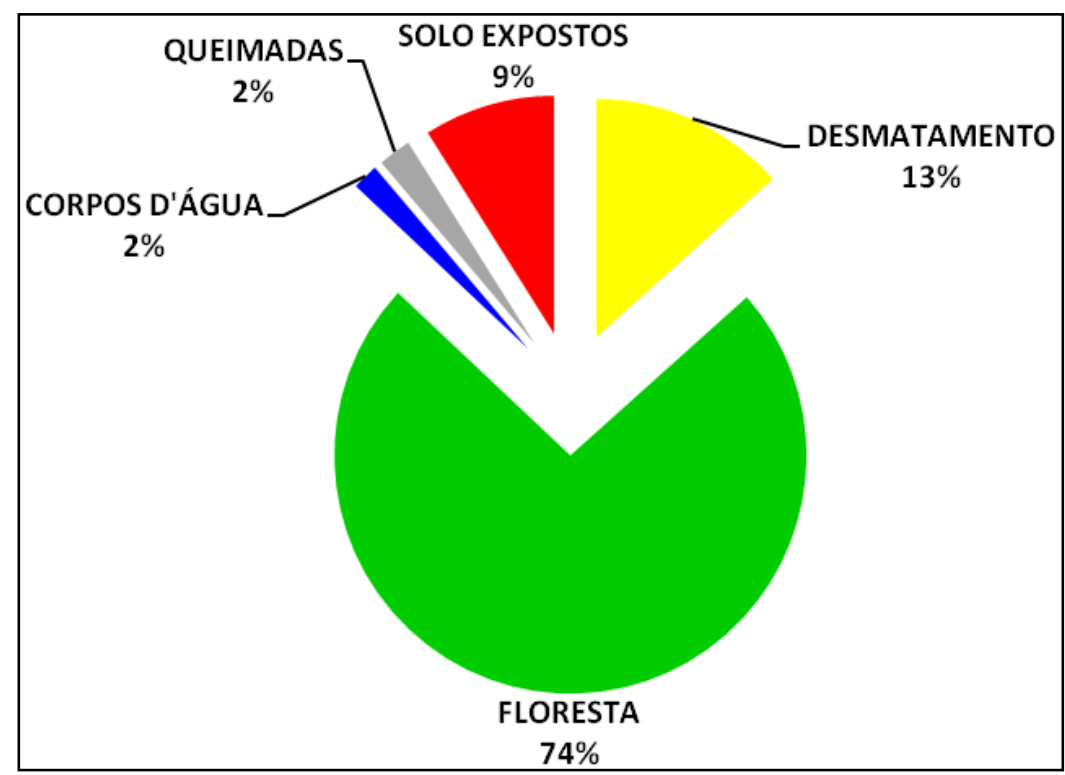

Gráfico 1: Classe do uso do solo e da cobertura vegetal da Estrada da EMADE no ano de 1990. 


\section{OS DESAFIOS DA GEOGRAFIA FÍSICA NA FRONTEIRA DO CONHECIMENTO \\ Instituto de Geociências - Unicamp \\ Campinas - SP \\ 28 de Junho à 02 de Julho de 2017}

Conforme essa configuração de paisagem ainda conservada, remete-se a Santos (2006, p. 157), "esse meio natural generalizado era utilizado pelo homem sem grandes transformações. As técnicas e o trabalho se casavam com as dádivas da natureza, com a qual se relacionavam sem outra mediação".

O homem explora a natureza para sua sobrevivência, porém, essa exploração com a inserção de novas técnicas, novas ferramentas muitas vezes sem respeitar os limitantes físico-naturais da paisagem causam impactos ambientais. Com a chegada dos grandes empreendimentos, a ação antrópica foi mais intensa, pois passou explorar a natureza prejudicando assim à mesma e a si mesmo.

Observa-se no gráfico 2, uma grande diferença nas classes de uso da terra e cobertura vegetal em 2015, como por exemplo, o desmatamento que aumentou para $37 \%$, classe de floresta que diminuiu em $48 \%$, e a classe dos corpos d'água foi de $3 \%$, evidências de classes queimadas foram $2 \%$ e classe de solos expostos de $10 \%$.

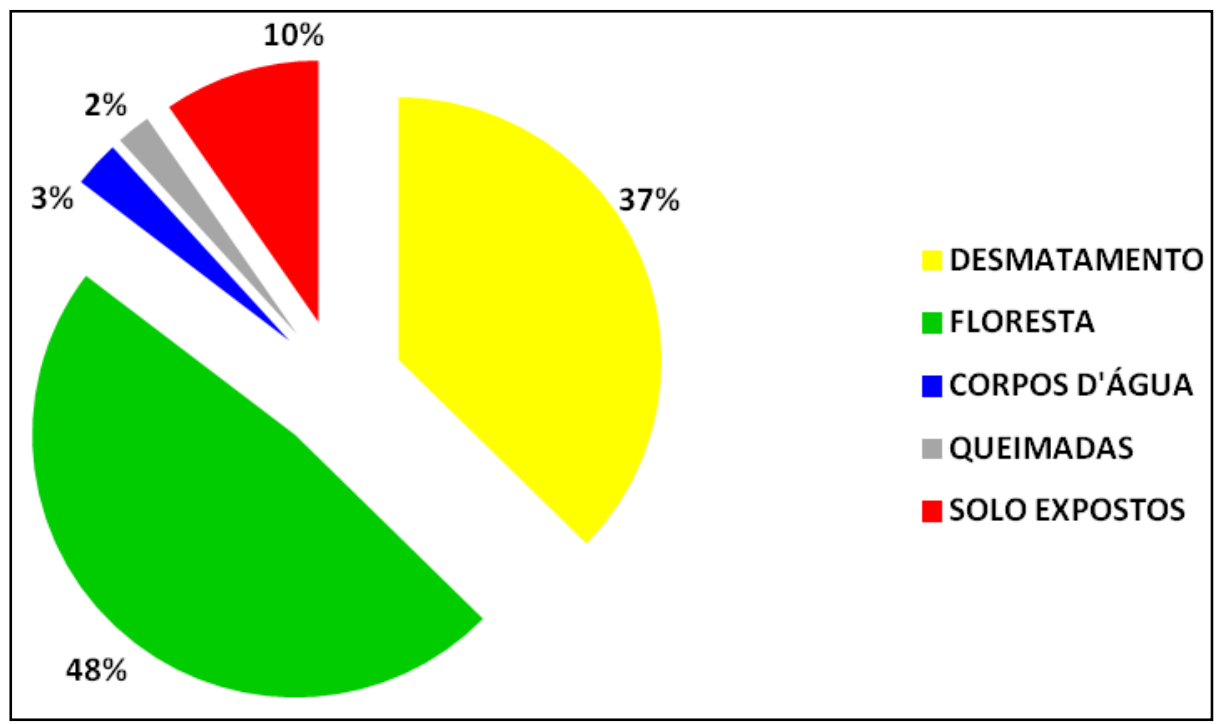

Gráfico 02: Classes do uso do solo e da cobertura vegetal da Estrada da EMADE no ano de 2015.

A substituição das áreas de florestas por áreas agropecuárias tem reflexo direto nas dinâmicas ambientais ao longo da estrada da EMADE, visto que a cobertura vegetal tem um papel primordial na conservação e resiliência dessa paisagem.

Na figura 5, verificou-se o modo que a ação antrópica passou a modificar a paisagem transformando-a e apropriando-a, pois, no local podemos observar que há uma grande área sem a cobertura vegetal. Assim, o homem, com suas técnicas, podem modificar a natureza de acordo com sua necessidade de adaptação, transformando uma paisagem natural com grande biodiversidade e tornando-a uma paisagem artificializada, suscetível a diversos impactos ambientais. 


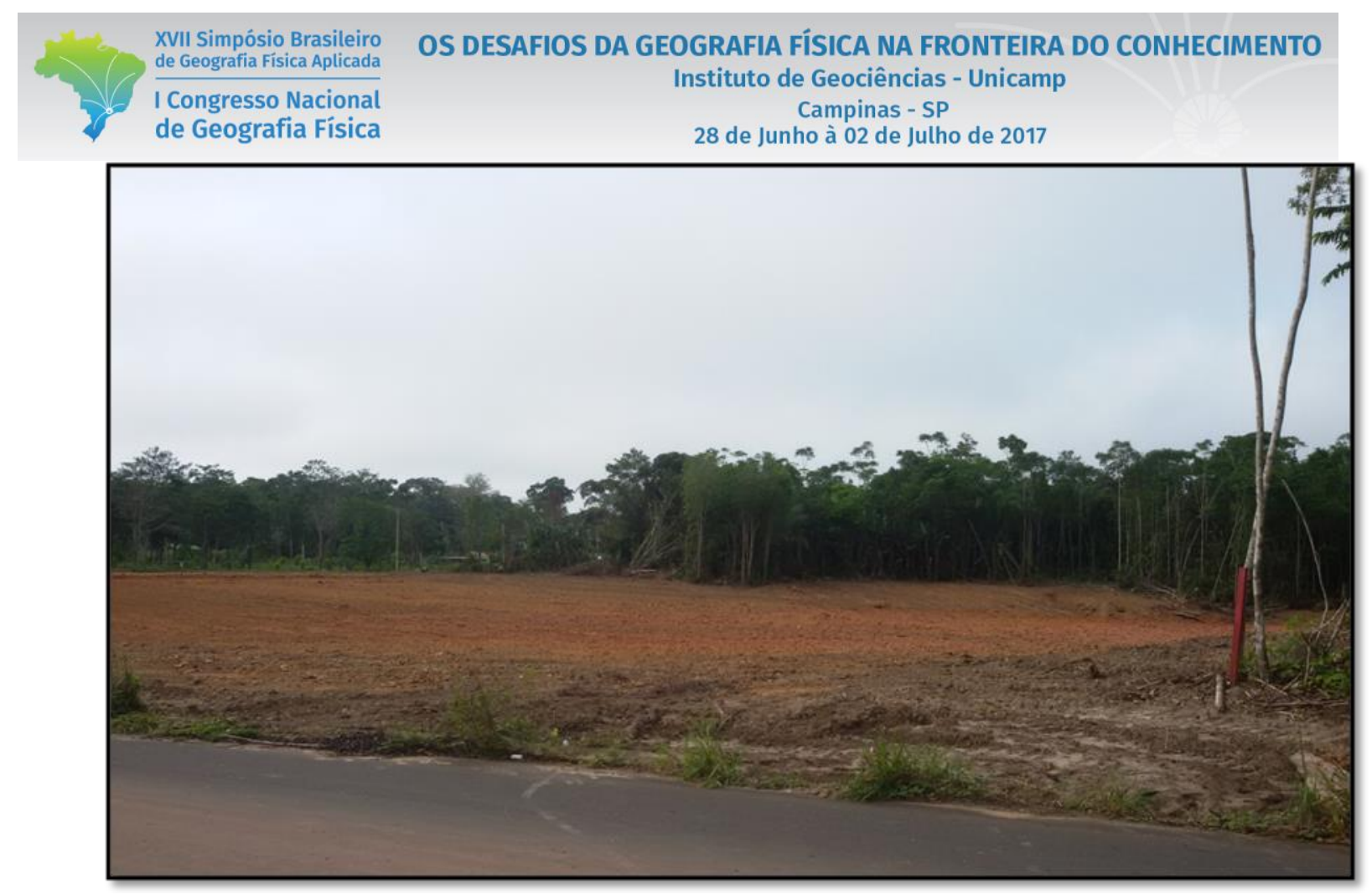

Figura 5: A ação do homem na natureza, mudança na paisagem, na margem da Estrada EMADE. Fonte: CONCEIÇÃO, 2016.

Assim, Leff (2006) apud Silva Neto \& Aleixo (2014, p. 158) considerou:

A apropriação pode ser definida como tornar a natureza própria à sociedade, ressaltando que essa apropriação da natureza não está ligada apenas ao ato de tirar benefícios dela, mas, fazer com que a sociedade e a natureza tenham uma relação simbiótica e recíproca, no qual, os reflexos de uma, estarão se manifestando diretamente na outra. (LEFF, 2006 apud SILVA NETO \& ALEIXO, 2014, p. 158).

$\mathrm{Na}$ figura 6 observaram-se áreas de queimadas, que acontecem por vários fatores, como para a agricultura, pecuária e entre outros, dessa forma, verifica-se a natureza pensada como mercadoria, por isso, as grandes alterações no meio ambiente geram diversos impactos de ordem socioambiental.

Moreira (2011, p. 120) ressalta que "o homem consegue os bens de que necessita intervindo na primeira "natureza", transformando-a. Transformando o meio natural, o homem transforma-se si mesmo". Desta forma, o homem passa ter outros olhares para a natureza, fazendo dela uma forma instrumental ao se apropriar para adquirir elementos naturais e onde esses elementos são retirados de forma desigual em forma de produção e de mercadorias. 


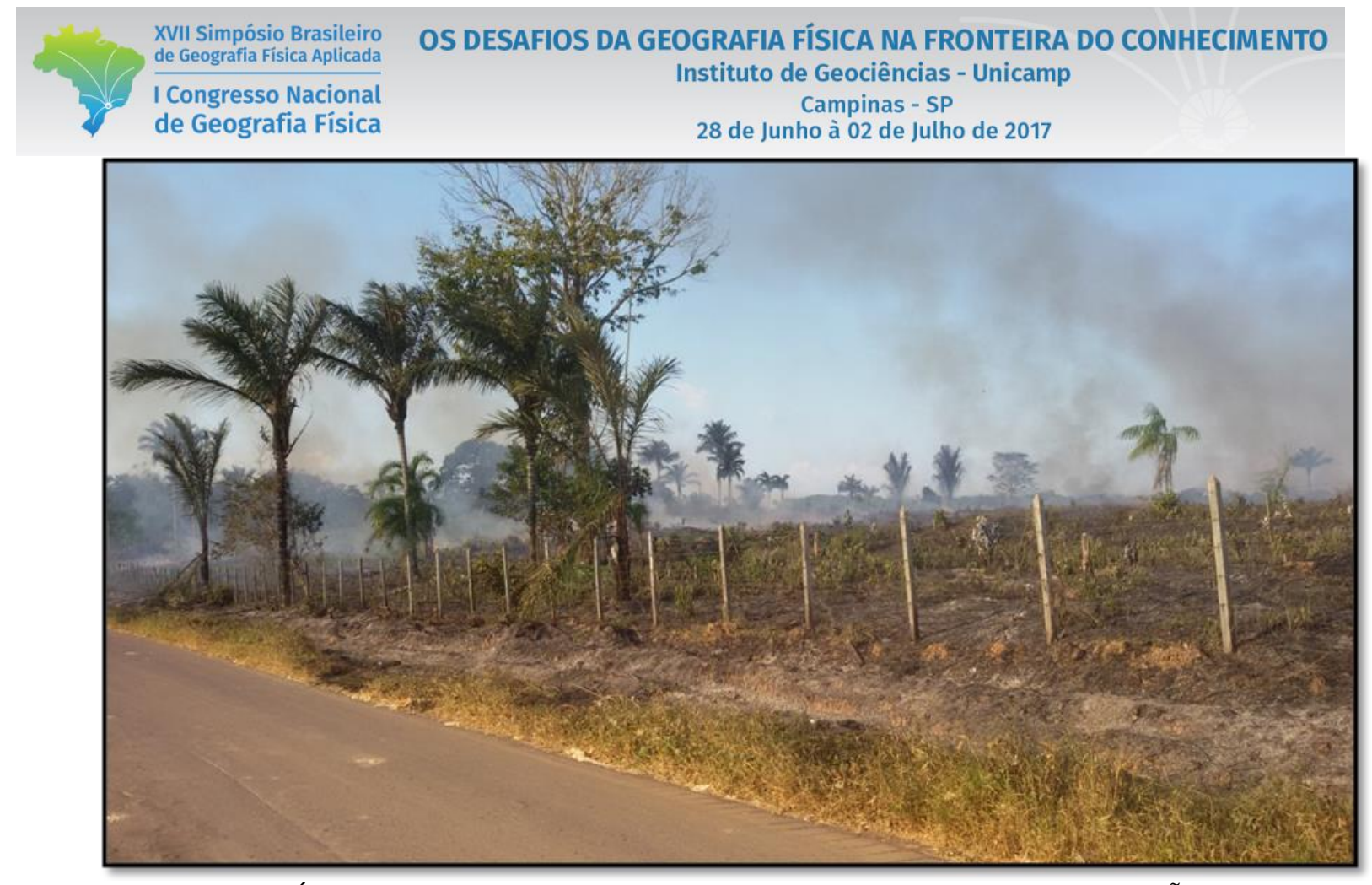

Figura 6: Área de Queimada nas margens da Estrada da EMADE. Fonte: CONCEIÇÃO, 2016.

Portanto, as margens da estrada foi possível verificar uma paisagem transformada intencionalmente visando atender os interesses de agentes sociais que tem em vista a rentabilidade sem considerar os fatores físico-naturais nesse importante espaço de biodiversidade que caracteriza a Amazônia brasileira.

\section{Conclusões}

Atualmente, o processo de apropriação da natureza na área da Estrada da EMADE na cidade de Tefé-AM, resulta na transformação gradativa, ou seja, no desmatamento da floresta, um fenômeno que vem se intensificando ao longo dos anos.

Notou-se que os fatores que contribuem para diminuição das áreas da floresta são a agricultura (plantação de mandioca), como forma de subsistência e atividade econômica, além da pecuária e a expansão das áreas de moradia por meio de comunidades que surgem a todo o momento.

Nesse contexto, verificou-se que a área da Estrada da EMADE sofreu um processo de intensa transformação de sua paisagem natural nas últimas décadas, que pode ser associado a diversos impactos socioambientais no presente e futuro, como a intensificação de processos erosivos, contaminação e poluição dos corpos hídricos, perda de fertilidade dos solos, assoreamentos dos rios e perda de biodiversidade. 


\section{Bibliografia}

CAMARA, G. Sistema de Informação Geográfica para Aplicações Ambientais e Cadastrais, uma nove visão, (Instituto Nacionais de Pesquisas Espaciais) INPE 1997.

CARVALHO, S. Análise temporal do Uso da terra e Cobertura Vegetal da Bacia Hidrográfica do Igarapé Xidarini Médio Solimões-am, (TCC, UEA) Tefé-Am, 2014.

CASSETI, V. Ambiente e apropriação do relevo. 2 ed. Contexto, 1995.

FITZ, P. R. Geoprocessamento sem Complicação \Paulo Roberto Fitz. --São Paulo: Oficina de textos, 2008.

FLORENZANO, T. G. Iniciação em Sensoriamento Remoto\Teresa Galloti Florenzano - São Paulo: Oficina de texto, 2007.

MENDOnÇA, F de A. Geografia e Meio Ambiente\Francisco de Assis. Mendonça 3º. ed. São Paulo: contexto, 1998- (caminhos de geografia)

MOREIRA, R. Pensar e ser em geografia: Ensaios de História, Epistemologia e Ontologia do Espaço Geográfico. -2. Ed - São Paulo: Contexto, 2011.

ROSS, J. Ecogeografia do Brasil: Subsídios para Planejamento Ambiental. São Paulo: Oficina de textos, 2006.

SANTOS, M. A Natureza do Espaço: Técnica e Tempo, Razão e Emoção / Milton Santos. -4. Ed. 2. Reimpr. -São Paulo: Editorada Universidade de São Paulo: 2006. -(Coleção Milton Santos; 1).

SILVA NETO J.C.A. da; ALEIXO, N.C.R. Apropriação da natureza e processos erosivos na Região do Médio Solimões-AM. Revista GeoUECE -Programa de Pós-Graduação em Geografia da UECE Fortaleza/CE, v. 3, nº 4, p. 151-176, jan./jun. 2014.

SILVA, D. Geotecnologias e a problemática dos resíduos sólidos urbanos em TEFÉ-AM. Dissertação (Mestrado em Ciências do Ambiente e Sustentabilidade na Amazônia) Universidade Federal do Amazonas, 2009. 